\title{
How homeopathy works-homeopathy and cancer
}

\begin{abstract}
We are reaching the threshold of our allopathic (cure with the opposite) medicine. The germs, we are trying to kill, adapt fast to the existing drugs and we need to come with new more powerful pharmaceutical drugs to kill them. In the last 10 years, $40 \%$ of the pharmaceutical drugs were new. The new drugs are more powerful, but have more side effects. Studies in Switzerland showed that more than $70 \%$ of the drugs have side effects. Are we loosing the fight with the germs? From here comes the necessity to look for alternative ways of cure. Homeopathy (cure with the similar) is one of these alternative ways. This article explains that homeopathy is usually herbal or mineral solution, but this solution has been so many times shaken and diluted that not even one molecule are left. If so, how it can cure. It cures through the unusual extraordinary ability of manifold shaken water to imprint on its structure through $\mathrm{H}$-bonds the frequencies of the substance that was dissolved in it. The structure of liquid water is complicated and dynamic; liquid water contains clusters of solid ice, which makes it inhomogeneous media with hysteresis properties. Hysteresis means the history is important. If history is important, this means that the water had imprinted on its structure the information (the frequencies) of the herbs that were dissolved in it. The article also explains that homeopathy is only one of the alternative ways of the new Informational Medicine, called also Vibrational or Quantum Medicine. Cancer is a jumbled mass of disintegrated cells multiplying out of control and the space between the cells is mostly water. Since homeopathy works through the extraordinary properties of water, it is expected to be effective in the fight with cancer.
\end{abstract}

Keywords: cancer, homeopathy, water hysteresis properties explained, info energy medicine

\section{Introduction}

Cancer, in its final state malignancy, is a jumbled mass of disintegrated cells, which multiply senselessly out of control. ${ }^{1}$ The cells cannot communicate and manifest collective behavior any more, neither they can form a useful architecture. Since the space between the cells is mainly water, in the case of cancer there should be something missing in the water, if the cells cannot communicate.

Speaking about the amount of water in the body, we should acknowledge its decline with aging. According to Russian studies, ${ }^{2}$ the amount of water in the fetus is $95 \%$, in the baby $-92 \%$, and it constantly decreases. Between age 20 and 30 the amount of water in the body is $70 \%$, between age 40 and 50 it is $50 \%$ (this is when the wrinkles appear). After the age of 70 , the amount of water in the body drops down to $30 \%$. This is when the bones become brittle because there is no enough water in them to keep them elastic. ${ }^{2}$

\section{The structure of water and its ability to imprint information}

The water is the greatest puzzle of Mother Nature. If you think that liquid water is a simple thing $-\mathrm{H}_{2} \mathrm{O}-$ you are very mistaken. The liquid water has a very complicated structure. On the first place, when the ice melts to form liquid water, only about half of the hydrogen bonds between the water molecules are destroyed. ${ }^{3}$

So the liquid water consists of large conglomerates (clusters) of solid ice swimming in the liquid state of water. This makes the water highly inhomogeneous and its properties nonlinear. Surrounding each cluster are two layers of not permanently connected water molecules. They are in dynamic equilibrium, which means that these molecules can stay connected to the cluster or leave depending on the external conditions.
Volume I2 Issue I - 2019

\author{
Maria Kuman \\ Holistic Research Institute, USA
}

Correspondence: Maria Kuman, Holistic Research Institute, I4I 4 Barcelona Dr., Knoxville, TN 37923, USA

Email holisticareI@gmail.com

Received: August 15, 2018 | Published: January 16, 2019
Russian scientists found that high in the Himalayas there was only one case of cancer in the last 20years. The local people were drinking water from the glaciers and claiming that this is their 'life water', which keeps them healthy. The Russian scientists went investigating the 'life water' taken from the melting glaciers of the Himalayas, hoping to reveal its secrets.

On clean glass surface they were dropping small amount of this "life water", then evaporating it, and looking at it through a microscope with resolution 140 . They found that the "life water" has crystalized in beautiful symmetric figures. Then they did the same with tap water and there were no figures at all. ${ }^{4}$

(Seiler in the magazine Zeiten Schrift cited Shauberger that the chlorination of drinking water not only destroys the structure of water, it influences very negatively our body and even our Spirit. It is detrimental not only to people, but to every living creature and plant on earth. As a result, the Germans started ozonating their water instead of chlorinating it - ozone kills the germs and does not do harm to people, animals, and plants.)

By using "life water", the Russian scientist Muldashev, was able to improve eyesight 30 times. ${ }^{4}$ However, it is not only the 'life water' of the Himalayas' glaciers that determines the low cancer rate of the local people. They live life free of stress, and scientific research showed that stress, negative emotions, and even negative thinking lead to chronic diseases and cancer ${ }^{1,4}$ by leaving imprint on the structure of water and our body is mostly water.

In liquid water, the clusters of solid ice change their size and shape when minerals or other substances are dissolved in it or under the influence of all kinds of external factors - temperature, atmospheric pressure, electric or magnetic fields. Based on this, we can claim that magnetized water exists and has properties different from the normal water. 
The water can reorganize its structure very fast and the ice clusters can change their size very fast. It was found in Russia that the size of the clusters changes in quants. ${ }^{4}$ The basic water quant is a cluster of 57 water molecules. However, it is possible to find ice clusters as big as 912 molecules, which are conglomerates of 16 cluster quants.

The ice clusters make the water inhomogeneous and their flexible dynamic structure allows imprint of all kind of information: music, human energy, even emotions and thoughts, ${ }^{4}$ which is called water memory. The physicist Dr. Wolfgang Ludwig of Los Angeles, consultant of the International Research Organization, said: "The water has the memory of an elephant ${ }^{4}$

Japanese studies of Masaru Emoto showed that classical music makes the water crystalize in beautiful symmetric patterns. ${ }^{5} \mathrm{He}$ also found that positive thoughts and positive emotions (like love) make the water crystalize in beautiful symmetric patterns. At the same time, he found that negative thoughts and negative emotions (like anger) make the water crystalize in ugly asymmetric patterns. ${ }^{5}$

Everybody knows that cancer results from stress, but we do not know how the stress causes cancer. If negative thoughts or negative emotions are present, this will influence negatively the structure of the water in the space between the cells. The energy of the intracellular liquid will drop, which will make the communication between the cells impossible. Once disintegrated, the cells will start multiplying senselessly and this means malignancy or cancer. ${ }^{6}$

Russian scientists found that the water structure is very sensitive to external influences. Electric current passing through the water causes one type of ice cluster configuration. Change in the atmospheric pressure causes another type of ice cluster configuration. When water is exposed to light, it has a third type of ice cluster configuration. ${ }^{4}$

Thus, each type of energy information is recorded in the water structure in a specific way, which means that the water is capable of recording information. I did my own measurements in 1981. I asked energy healer, who heals with hands, to do clockwise movements on top of a bowl with water. I measured with sensitive IR equipment the emission of this water and I found strong infrared emission from it. ${ }^{7}$

I was surprised that the water left at room temperature was still emitting IR energy in the second and third day, ${ }^{7}$ while the Brownian movement of the water molecules was supposed to dissipate this energy overnight. I learned a few years later, when I started working nonlinear physics that the human electromagnetic field is nonlinear and nonlinear fields do not dissipate easily.

Similar experiments with water, which hand-healers treated for 3 minutes, were also done in Russia some years later. They showed that the treated with hands water was emitting 300\% more energy than the control. ${ }^{4}$ Dr. Zvenin explained this with the dynamic of ice-clusters' configurations - changes in the configuration of one ice cluster lead to changes in the configuration of all ice clusters. ${ }^{4}$ This can happen only if the ice clusters are related strongly in a nonlinear way.

Russian investigations of Acad. Goskov ${ }^{4}$ showed that when the energy of positive emotions is imprinted on water, wheat seeds watered with such water germinate much faster and the degree of the sped-up germination depends on the duration of the impact of positive emotions. The Russian scientist Prof. Bolotova ${ }^{4}$ showed that negative emotions, in particular anger, not only changed the clusters' structure, it changed some of the water molecules from $\mathrm{H}_{2} \mathrm{O}$ to $\mathrm{D}_{2} \mathrm{O}$, and $\mathrm{D}_{2} \mathrm{O}$ is toxic for the body.
The dynamic flexible structure of the water is even influenced by our thoughts. If people with strong energy fields can freeze the arrow of an instrument and not allow it to move, such people could and would change the water structure. An energy healer in Russia changed the water conductivity with 7,000 microamperes. ${ }^{4}$ On the background of all this, even the mental effort of Jesus to change the water into wine at the wedding in Canaan seems quite in reach.

\section{Homeopathy and water structure}

The French immunologist Jacques Benveniste ${ }^{9}$ did research with anti-bodies. He noticed that the biological effect of anti-bodies was still there even when the solution was so diluted that anti-bodies were no longer present. This reminded him homeopathy. He stated that the water must have the ability to memorize. Only memorizing could explain his experiment as well as the fact that the homeopathic remedies work even when the substance is so diluted that not even one molecule of the substance is left. ${ }^{9}$

When asked, how the water does the memorizing, Benveniste's answer was I am immunologist, not a physicist. Being a physicist, I would try to explain how the water memorizes the information of the substance that was diluted in it. The liquid water has inhomogeneous structure because only about half of the hydrogen bonds in the ice were destroyed during the process of melting. So the liquid water is ice-clusters swimming in liquid water.

Every media, which is inhomogeneous, exhibit nonlinear properties ${ }^{10}$ and the liquid water containing ice clusters is strongly inhomogeneous. One of these nonlinear properties is hysteresis, which means history is important, and the fact that history is important means memorizing past events. Thus, the inhomogeneous structure of water guarantees ability to memorize.

However, if Benveniste ${ }^{9}$ would use the word hysteresis instead of memory, when explaining that the biological effect of anti-bodies was still present when the solution was so diluted that anti-bodies were no longer present, probably it would be accepted. However, since he used the word memory, many scientists jumped on him.

The experiment of Benveniste ${ }^{9}$ explains why the homeopathic remedies work even when the substance is so diluted that not even one molecule of the substance is left. This means that the specific vibrations of the nonlinear electromagnetic field of the molecules dissolved in the water are imprinted on the complicated inhomogeneous dynamic nonlinear structure of water.

The water structure is dynamic because each cluster has two layers of loosely connected water molecules. They can stay connected to the cluster or leave depending on internal or external conditions. If the conditions require these two layers to become disconnected from the cluster, another two layers of the cluster become loose and free to leave if the conditions change.

The critics of the Benveniste's idea of memorizing water didn't curb his enthusiasm for farther experimenting. Benveniste was a scientist with a vision and he claimed based on his farther experiments that biomolecules communicate with their receptors by sending low frequency electromagnetic signals, which the receptors pick up like radios tuned to specific wavelength.

He recorded these signals digitally and by playing them back in the absence of the molecules, he was reproducing the biochemical effect, as if the molecules were there. By playing the electromagnetic 
signal, he was able to trigger the defense response of neutrophils to kill invading cells, just as the presence of the molecules would do.

Luc Montagnier - the Nobel Prize winner of year 2014 for his research on HIV virus - found that the DNA of HIV virus, when diluted in water, created electromagnetic signal, which still existed even at very high dissolutions, when DNA molecules were no longer present. He filtered the water containing the DNA of HIV virus, so that no molecule of DNA was left in the filtrate, but the DNA signal of the HIV virus was still there, and so was its detrimental effect. ${ }^{11,12}$

Acad. Peter Garyaev in Russia ${ }^{4}$ is marching ahead of our time - he is already using information signals for healing. First, he injected 30 rats with aloxan - a poison that kills the pancreatic cells and causes diabetes. 24 of the rats died. The surviving 6 , when treated with information from healthy pancreas, recovered completely. Here is how it was done.

Laser light, after reflection from mirrors, was made to be stationary. Then it was focused on the pancreas of a healthy rat and the laser memorized the vibrations of the healthy pancreas. This information was transformed from being recorded with laser light to being recorded with radio waves. The 3 rats, receiving the information from the pancreas of healthy rat recorded with both laser light and radio waves, completely recovered in 3 days. The other 3 rats, receiving only radio wave information, recovered in 9days.

Acad. Goryaev concluded that obviously we could also heal ourselves with electromagnetic waves. ${ }^{4}$ Another Russian scientist, Acad. Grabovoi, outlined the importance of avoiding negative information entering the water of our body or to find ways to get rid of the damage of this negative information before it has sank at physical level. ${ }^{4}$

When cancer is concerned, I want to draw your attention to the fact that some years ago I read in the Russian literature that if cancer cells were sucked out with injection, severely shaken for a while and then injected back, the cancer would disappear (I have this cited in my book). ${ }^{1}$

And I want to draw your attention to the fact that homeopathic remedies are prepared by diluting 1:10 up to 30times and shaken hundreds of times after each delusion. When we shake, we cut hydrogen bonds. This decreases the size of the ice clusters and frees hydrogen bonds, which increases the ability of water to imprint information.

Not only this, the shaking of water would create turbulence eddies, which at shaking brake into smaller eddies, etc. The more we shake the water, the more nonlinear it becomes and its ability to imprint information increases.

\section{Homeopathy is cure with the similar- how this works}

Some scientists did try to explain how the cure with the similar works, but I am not going to list here their hypothesis because none of them makes sense to me. Their explanations do not make any sense because none of them knew nonlinear physics and as we said the liquid water is strongly inhomogeneous and its properties are strongly nonlinear. Also, as the water is shacked it becomes more nonlinear.

We said that everything dissolved in water changes the water structure - ions, germs, or substances. Now, imagine a person has contracted a germ and this germ has changed the structure of his body's water. Homeopathy is cure with the similar. This means that when you try to cure the person with homeopathic remedy, you give him a substance dissolved in many times shaken water, which leads to the same structural changes in the water as the changes caused by the germ.

Cure done with the similar would make sense only to a person acquainted with nonlinear physics because he knows that accumulation of quantity leads to a new quality state. When the distortion of the water structure, which the germ caused, is summed up with the distortion of water structure, which the homeopathic remedy caused, the critical level $\mathrm{E}_{\mathrm{c}}$ (of distorted water structure) is reached, which the body can tolerate. $\mathrm{E}_{\mathrm{c}}$ is called bifurcation point because after it the body must shift to a new state.

When the critical point of tolerated water-structure distortion is reached, the self-regulated mechanism kicks in. All regulation mechanisms are handled by the weak human nonlinear electromagnetic field (NEMF). It is a field 1,000 times weaker than the biocurrents of the body. While the biocurrents are measured in milliamperes (thousandth of the ampere), the NEMF is measured in microamperes (millionth of the ampere). ${ }^{14}$

The author of this article developed and patented sensitive equipment capable of measuring this weak NEMF and spent 40years of her life measuring its role in ruling and regulating everything in the body. Since all organs are subordinated to the Subconscious, the NEMF rules and regulates everything in the body from the Subconscious. It is deliberately done so because when our life is threatened and we need to make important decision to survive, we don't want to be bothered with information about the functioning of our organs. ${ }^{15}$

Thus, what homeopathic remedies do is - they shift the distortions in the body's water structure caused by the virus to the critical point at which the regulating mechanism of the NEMF kicks in and do the repair. Since the Subconscious house the NEMF, the homeopathic remedies work through the Subconscious as many other modality of the alternative medicine do (such as acupuncture). ${ }^{7}$

The allopathic medicine, which cures with the opposite (the pharmaceutical drug counteract the virus), makes the immune system weaker and this is called secondary immune deficiency. ${ }^{4}$ Since homeopathic medicine cure with the similar by enhancing the changes, which the virus created, until the self-regulating immune mechanisms kick in, the homeopathy would strengthen the immune system mechanisms.

\section{Conclusion}

Thus, when negative information is present: from negative emotions or negative thoughts, the human NEMF is suppressed and this on the first place influences the water in the body in a negative way. If we were smart, we would do our best to avoid negative thinking. The other option is to learn to eliminate the negative impact of negative thinking before it has sunk to physical level as a disease. This means preventive medicine. Not only is homeopathy going to be accepted as one of the modalities of the new Info-Energy or Quantum Medicine, it would be used more and more for prevention of diseases.

From acupuncture we know that all organs of the body are holographically represented on the surface of the body: on the palms, on the feet, on the ears, on the eyes (and in our voice). All 
acupuncturists know that to cure the chronic disease of certain organ they could treat with acupuncture the point of the diseased organ on any of these holographic representations.

Thus, we know that the Subconscious rules and regulates the functioning of all our organs. We also know that all organs are holographically represented not only on the surface of the whole body, but also on ears, eyes, etc. Therefore, the Subconscious must work on the holographic principle (and it does).${ }^{15}$ For that reason, both the diagnosis and the early diagnosis called prognosis of diseases is done either through pulse diagnosis, or voice analysis, ${ }^{15}$ or iris diagnosis. ${ }^{16}$

Acupuncture in ancient time was basically used for prevention. Ancient Chinese wisdom says: "Only the bad doctor cure, the good doctor knows how to prevent the disease." The acupuncturist would check up the pulse on the neck, hands, and legs and compare them (called pulse diagnosis). When a slight deviation from norm was detected, usually one acupuncture treatment was enough to eliminate it, and the person would stay healthy.

In ancient China, everybody was going to his doctor acupuncturist for check up four times a year, and paying a fixed annual fee. If a disease would appear, this meant that the doctor didn't do his preventive treatments right. Then to cure the already onset disease, the doctor was supposed to do for free the acupuncture treatments necessary to cure the disease - usually 14 daily acupuncture treatments. Thus, it was in the interest of the doctor to keep his clients healthy.

So, if the cancer cells multiply senselessly as a result of lack of communication among them and the liquid between the cells is mostly water, there must be changes in the intracellular liquid water.7 If so, homeopathic remedies, which are many times diluted and many time shaken water, which had imprinted the frequencies of the substance dissolved in it, could be expected to have positive impact on cancer.

However, since the cure of chronic diseases (and cancer) is slow, difficult, and unpredictable, ${ }^{18}$ we should be looking for ways to diagnose early or predict the oncoming cancer disease through pulse diagnosis, ${ }^{18}$ voice diagnosis, ${ }^{15}$ or iris diagnosis ${ }^{16}$ and prevent it either with acupuncture or homeopathic remedy that would restore the health balance and prevent the disease.

The ancient Chinese said: "Trying to cure an already onset disease is like trying to make weapons when the enemy is already in your yard". ${ }^{17}$ If so, prevention should be our final goal. Thus, the medicine of the $21^{\text {st }}$ century is going to be preventive and it is going to restore the health balance with frequencies. We can name the new medicine Info Energy Medicine, Vibrational Medicine, or Quantum Medicine. ${ }^{14}$ The homeopathic medicine in its basis is vibrational medicine, and its impact of the body is mild or gentle.

It is high time for our medicine to switch to remedies, which are mild or gentle to the body as the homeopathic remedies are. And the final goal would be to find homeopathic remedies, which prevent diseases. Let us work toward finding not only a homeopathic remedy for cancer, but finding a homeopathic remedy that prevents cancer.

\section{Acknowledgment}

None.

\section{Conflicts of interest}

Author declare there is no conflict of interest toward this article.

\section{References}

1. Kuman M. What Everybody Needs to Know about Chronic Pain, Chronic Diseases and Cancer. Health and Happiness Books; 1993.

2. Parfenov I. Zkalivanie Cheloveka (Strengthening of Man). 1965.

3. Kuman M. Quantum Biophysics. Japan: Sofia University Press; 1975.

4. Tihoplav V, Tihoplav T. Garmonia Haosa. Russia: The Harmony of the Chaos; 2003.

5. Emoto M. What the Bleep Do We Know? 2004

6. Kuman M, Cancer Is a Lost Control over the Cellular Growth Caused by Stress. Advances in Complimentary and Alternative Medicine. 2018;1(4)

7. Kuman M. The Acupuncture Meridians Are Wave Sensitive. Int $J$ Complement Alt Med. 2017;42(2):97-112.

8. Davenas E, Beauvais F, Amara J, et al. Human basophil degranulation triggered by very dilute antiserum against IgE. Nature. 1998;333(6176):816-818

9. Thomas I. Medical Hypothesis. 2000;54:33-39.

10. Kuman M. Organic Polymer Conductivity - a Nonlinear Approach Synthetic Metals. 1988;27:A89.

11. Montagnier L. Homeopathic Signals from DNA. Science and Society 2010;48:36-39.

12. Montagnier L. Electromagnetic Signals from DNA. Science and Society. 2010;48:40-43.

13. Kuman M. Measuring the Role of Way of Thinking in Life and Medicine Chronicle of Medicine and Surgery. 2018;2(1):94-98.

14. Kuman M. Holographic (Quantum) Way of Seeing, Hearing and Memorizing and Their Use for Diagnosis. Research in Medicine and Engineering Science. 2018;5(3):2018.

15. Kuman M. Info Energy Medicine - Voice Sound for Diagnosis. Journal of Natural and Ayurvedic Medicine. 2018;2(3):2018.

16. Kuman M. Info Energy Medicine and Iris Diagnosis - Eventual Cure with Light. Advances in Complimentary and Alternative Medicine. 2018;2(4):2018.

17. Kuman M. The Difficult and Unpredictable Healing of Chronic Diseases Explained by the Nonequilibrium Theory of Prigogine. International Journal of Integrated Medicine. 2018;43(1):19-28.

18. Kuman $\mathrm{M}$. The acupuncture meridians are wave sensitive. International Journal of Integrated Medicine. 2017;42(2):97-112, 